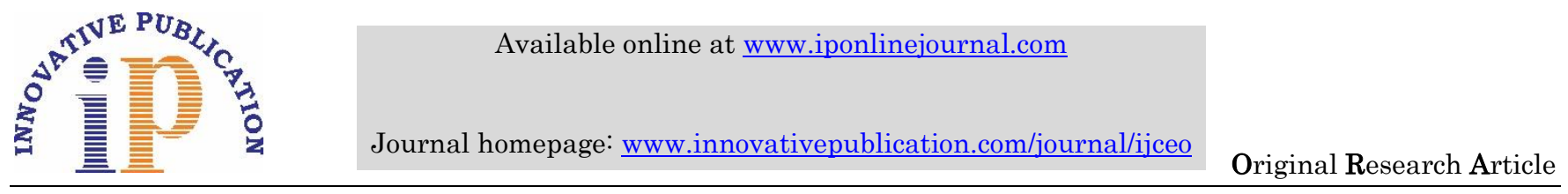

\title{
Prevalence of dermatological lesions in diabetic retinopathy
}

\author{
Shimna CP${ }^{1 *}$, Sheldon Goudinho², Joan Felicita Samson ${ }^{3}$, Jasmine Mary Jacob ${ }^{4}$, Soumya Gopakumar ${ }^{5}$ \\ ${ }^{\mathbf{1}}$ Assistant Professor, ${ }^{2-4}$ Professor, ${ }^{5}$ Associate Professor, ${ }^{1,2,4}$ Dept. of Ophthalmology, ${ }^{3}$ Dept. of Dermatology, ${ }^{5}$ Dept. of Community \\ Medicine, ${ }^{1-5}$ Dr. Somervell Memorial CSI Medical College, Karakonam, Thiruvananthapuram, Kerala, India
}

\section{Article Info}

Received: $21^{\text {st }}$ January, 2019

Accepted: $26^{\text {th }}$ April, 2019

Published Online: $9^{\text {th }}$ September, 2019

Keywords: Diabetes Mellitus (DM), Diabetic Retinopathy (DR), Dermatological lesions, Diabetic dermopathy, Xerosis.

\begin{abstract}
Background and Objectives: There are several studies which gives the prevalence of dermatological lesions as well as prevalence of Diabetic Retinopathy (DR) in Diabetes Mellitus (DM) patients. A few studies have also looked upon the association between diabetic dermopathy, which is the commonest dermatological lesion in DM and retinopathy. However, there are no studies available in literature which gives the prevalence of Dermatological lesions in DR patients. This study is undertaken to find out the same.

Materials and Methods: 170 DR patients between 40-70 years of age with history of DM of at least five years duration were included in the study. Skin and retina of these patients were examined. The study period was 12 months.

Results: 170 DR patients included in the study were in the age group of 42 years to 70 years with a mean age of 59.15(SD 6.76) years. The duration of DM in the study group was 5 to 35 years with a mean duration of 13.43 years (SD 5.60). 147(86.47\%) among 170 patients had various dermatological lesions. Most prevalent dermatological lesions noted among the patients were Diabetic dermopathy (shin spots), Xerosis, Idiopathic Guttate Hypomelanosis (IGH), Icthyosis, Intertrigo, Tinea Versicolor, Chronic Paronychia and Tinea Unguium.

Conclusion: Prevalence of Dermatological lesions in Diabetic Retinopathy patients was $86.47 \%$, the most common being Diabetic Dermopathy (shin spots) which was $42.94 \%$.
\end{abstract}

\section{Introduction}

Diabetes Mellitus (DM), an endocrine disorder is estimated to be $4.4 \%$ (366 million adults) for all age-groups globally by the year $2030 .{ }^{1}$ It is also estimated to be $5.4 \%$ (300 million adults) among the adults globally by the year $2025 .{ }^{2}$ It is said that India will have a maximum increase in DM by 2030 among the developing countries and it is estimated that about 79.4 million individuals will be affected. ${ }^{3}$

DM can affect almost all organ systems in the body and can cause microvascular complications like neuropathy (nervous system damage), nephropathy (renal system damage) and retinopathy (eye damage) as well as macrovascular complications like cardiovascular disease, stroke, and peripheral vascular disease leading to nonhealing ulcers and gangrene which end up in amputation. ${ }^{4}$

There are several studies in literature which gives a description of different complications of DM especially complications that occur in skin. ${ }^{5-11}$ Few studies gives the association between complications of diabetes like retinopathy and dermatological lesion like diabetic dermopathy. ${ }^{12-18}$ Also, there are several studies in literature which gives the prevalence of DR in DM patients. ${ }^{19-23}$ Frequency of diabetic dermatological lesions in DR is not available in literature and it is difficult to know the exact nature of association between these two, though both are considered to be the complications of DM.

The purpose of this study was to investigate on the prevalence of dermatological lesions in patients with diabetic retinopathy attending the diabetic retinopathy clinic.

\section{Materials and Methods}

As there was no data available in the literature, a pilot study was conducted. Sample size was estimated to be 170 taking the properties of Xerosis (dermatological lesion) as $90 \%$ with reference to the pilot study with an allowable error of $5 \%$ and using the formula $\frac{1.96^{2} \times p \times q}{d^{2}}$.

A cross sectional study was conducted on 170 patients with diabetic retinopathy having diabetes mellitus of at least 5 years duration, aged between 40-70 years, attending the Departments of Dermatology and Ophthalmology in a tertiary centre of South India, for a period of 12 months, from 2017 to 2018. Patients suffering from ophthalmological conditions like hypertensive retinopathy, vascular occlusion and advanced cataract that may affect the findings were excluded from the study.

A questionnaire, which is semi structured was used to collect the data. The dermatological examination was done

\footnotetext{
*Corresponding Author: Shimna CP, Assistant Professor, Dept. of Ophthalmology, Dr. Somervell Memorial CSI Medical College, Karakonam, Thiruvananthapuram, Kerala, India

Email: shimna1978@gmail.com

http://doi.org/10.18231/j.ijceo.2019.073
} 
by a dermatologist under proper day light and if needed, using hand held magnifying lens. Examination of the retina was done by an Ophthalmologist using indirect ophthalmoscopy of dilated fundus, fundus photo, fundus fluorescein angiography and optical coherence tomography of the macula.

Socio-demographic details of patients including name, age, sex, educational status and occupation, questions on diabetes mellitus like duration of diabetes, medications and associated conditions were included.

The collected data was entered in MS Excel software and was analysed using SPSS ver 16. The study protocol was approved by the Institutional ethical committee (ICE). Privacy and confidentiality of the patients were maintained and those detected to have any lesion were managed appropriately.

\section{Results}

170 patients who had DR were included in the study. The range of age was from 42 years to 70 years. The mean age was 59.15(SD 6.76) years. The duration of diabetes mellitus in this group was 5 to 35 years with a mean duration of 13.43 years (SD 5.60). Out of the 170 patients, 149 had some form of education of which, majority $117(68.82 \%)$ were housewives.

There was a slight female preponderance with 72 males (42.35\%) and 98 females (57.65\%) among the 170 patients (Fig. 1).

Of the 170 diabetic patients included in this study, 15(8.82\%) had Very Mild Non Proliferative Diabetic Retinopathy (NPDR), 51(30\%) had Mild NPDR, 57(33.53\%) had Moderate NPDR, 18(10.59\%) had Severe NPDR, 25(14.71\%) had Proliferative Diabetic Retinopathy (PDR) and 67(39.41\%) had Clinically Significant Macular Edema (CSME). Figure 2 shows the gender distribution of Diabetic Retinopathy.

54 patients $(31.76 \%)$ were on Oral hypoglycemic agents (OHA), 31(18.24\%) were on Insulin and 85(50\%) were on both OHA \& Insulin. Only 64(37.65\%) out of the 170 patients had good control of DM. 80(47.06\%) out of 170 patients had Systemic Hypertension (HTN) along in addition to DM with a duration of 0.0833 (1 month) to 23 years with a mean duration of 3.71 years (SD 5.50).

147 among 170 DR patients had different types of dermatological lesions, the prevalence being $86.47 \%$. Dermatological lesions among poor glycemic control DM patients had a prevalence of $51.18 \%$ which was higher as compared to $32.94 \%$ among good glycemic control DM patients.

Out of 147 patients, the most prevalent dermatological lesions noted were diabetic dermopathy, Xerosis, Idiopathic Guttate Hypomelanosis (IGH), Icthyosis, Intertrigo, Tinea Versicolor and Chronic Paronychia, while the less prevalent ones were Eczema, Melasma, Lichen Amyloidosis, Varicose vein, Fissure feet, Pigmented Purpuric Dermatosis (PPD), Dermatosis Papulosa Nigra (DPN), Sclerodactyly, Plain warts, Macular Amyloidosis, Cherry Aneurysm,
Xanthelasma Palpebraraum, Photodermatitis, Skin tags, Onychomycosis, Onychogryphosis and Prurigo.

$73(42.94 \%)$ patients had diabetic dermopathy, 56(32.94\%) had Xerosis, 49(28.82\%) had IGH, 41(24.12\%) patients had Icthyosis, $11(6.47 \%)$ patients had Intertrigo, 9(5.29\%) patients had Tinea Versicolor, $8(4.71 \%)$ patients had Chronic Paronychia and 7(4.12\%) patients had Tinea Unguium.

4(2.36\%) patients had Eczema, 3(1.76\%) had Melasma, $3(1.76 \%)$ had Lichen Amyloidosis, 3(1.76\%) had Varicose vein, $2(1.18 \%)$ had Fissure feet, $2(1.18 \%)$ had Pigmented Purpuric Dermatosis (PPD), 2(1.18\%) had Dermatosis Papulosa Nigra (DPN), 2(1.18\%) had Sclerodactyly, $2(1.18 \%)$ had Plain warts, $1(0.59 \%)$ had Macular Amyloidosis, 1(0.59\%) had Cherry Aneurysm, 1(0.59\%) had Xanthelasma Palpebrarum, 1(0.59\%) had Photodermatitis, $1(0.59 \%)$ had Skin tags, $1(0.59 \%)$ had Onychomycosis, $1(0.59 \%)$ had Onychogryphosis and $1(0.59 \%)$ had Prurigo (Fig. 3). Table 1 and 2 shows the gender distribution of Dermatological lesions among Diabetic Retinopathy patients.

\section{Discussion}

Poor glycemic control might lead on to prolonged hyperglycemia. Prolonged hyperglycemia causes microcirculation and glycosylation of proteins which in turn results in complications in various organ systems of the body. Kidney, retina, nerves, and skin are the most commonly affected which manifests as renal failure, retinopathy, neuropathy and Diabetic dermopathy. ${ }^{24-25}$ In our study, Dermatological lesions among DR patients who had poor glycemic control had a prevalence of $51.18 \%$ which was higher as compared to $32.94 \%$ among good glycemic control patients.

Skin (Dermatological) disorders in DM can occur due to diabetic vascular abnormalities, cutaneous infections, treatment complications especially with Insulin, associated hyperlipidemia and other miscellaneous causes. Lesions like Diabetic dermopathy, erysipelas-like erythema, Diabetic rubeosis, leg ulcers and wet gangrene of the foot are due to vascular abnormalities. Non clostridial gas gangrene, candida albicans etc. are due to cutaneous infections. Insulin reactions can lead on to insulin lipodystrophy and associated hyperlipidemia can cause acanthosis nigricans, eruptive xanthomas and skin tags. Other manifestations like diabetic bullae, pruritis, waxy skin, scleroderma diabeticorum, vitiligo, lichen planus etc. are also noticed in DM. ${ }^{26}$

In our cross sectional study, 170 patients with DR were included, who all had suffered from type $2 \mathrm{DM}$ for at least 5 years. Prevalence of dermatological lesions among these patients was found to be $86.47 \%$, and the most Prevalent Dermatological lesion was Diabetic dermopathy (shin spots) which was $42.94 \%$. Other common dermatological lesions noted were Xerosis, IGH, Icthyosis, Intertrigo, Tinea Versicolor and Chronic Paronychia.

George and Walton also reported that Diabetic dermopathy (diabetic shin spots) is the commonest skin condition that occurs in patients with DM. ${ }^{27}$ A study 
conducted among $125 \mathrm{DM}$ patients by Kalsy et al found that the most frequent skin lesions was diabetic dermopathy. ${ }^{28}$ In another study done by Chatterjee et al among 490 Type 2 diabetics, infections, Xerosis, hair loss beneath the knees and diabetic dermopathy were the most frequent. ${ }^{29}$

A thorough search of literature could not give any studies which investigated on the prevalence of diabetic dermatological lesions in DR patients. Though both DR and Dermatological lesions are considered to be the complications of DM, we could not demonstrate the exact nature of association between these two in our study and further studies are required to do so.

Table 1: Gender distribution of most prevalent Dermatological lesions among DR patients

\begin{tabular}{|c|c|c|c|}
\hline Dermatological Lesions & Total & Males & Females \\
\hline Diabetic dermopathy (shin spots) & $42.94 \%$ & $19.41 \%$ & $23.53 \%$ \\
\hline Xerosis & $32.94 \%$ & $12.94 \%$ & $20 \%$ \\
\hline IGH & $28.82 \%$ & $7.06 \%$ & $21.76 \%$ \\
\hline Icthyosis & $24.12 \%$ & $13.53 \%$ & $10.59 \%$ \\
\hline Intertrigo & $6.47 \%$ & $0.59 \%$ & $5.88 \%$ \\
\hline Tinea Versicolor & $5.29 \%$ & $4.12 \%$ & $1.18 \%$ \\
\hline Chronic Paronychia & $4.71 \%$ & $2.94 \%$ & $1.76 \%$ \\
\hline Tinea Unguium & $4.12 \%$ & $1.76 \%$ & $2.35 \%$ \\
\hline
\end{tabular}

Table 2: Gender distribution of less prevalent Dermatological lesions among DR patients

\begin{tabular}{|c|c|c|c|}
\hline Dermatological Lesions & Total & Males & Females \\
\hline Eczema & $2.36 \%$ & $1.18 \%$ & $1.18 \%$ \\
\hline Melasma & $1.76 \%$ & 0 & $1.76 \%$ \\
\hline Lichen Amyloidosis & $1.76 \%$ & 0 & $1.76 \%$ \\
\hline Varicose veins & $1.76 \%$ & $0.59 \%$ & $1.18 \%$ \\
\hline Fissure feet & $1.18 \%$ & 0 & $1.18 \%$ \\
\hline PPD & $1.18 \%$ & 0 & $1.18 \%$ \\
\hline DPN & $1.18 \%$ & 0 & $1.18 \%$ \\
\hline Sclerodactyly & $1.18 \%$ & $0.59 \%$ & $0.59 \%$ \\
\hline Plain warts & $1.18 \%$ & 0 & $1.18 \%$ \\
\hline Macular Amyloidosis & $0.59 \%$ & 0 & $0.59 \%$ \\
\hline Cherry Aneurysm & $0.59 \%$ & 0 & $0.59 \%$ \\
\hline Xanthelasma Palpebrarum & $0.59 \%$ & $0.59 \%$ & 0 \\
\hline Photodermatitis & $0.59 \%$ & $0.59 \%$ & $0.59 \%$ \\
\hline Skin tags & $0.59 \%$ & 0 & 0 \\
\hline Onychomycosis & $0.59 \%$ & $0.59 \%$ & $0.59 \%$ \\
\hline Onychogryphosis & $0.59 \%$ & 0 & 0 \\
\hline Prurigo & $0.59 \%$ & $0.59 \%$ & \\
\hline
\end{tabular}

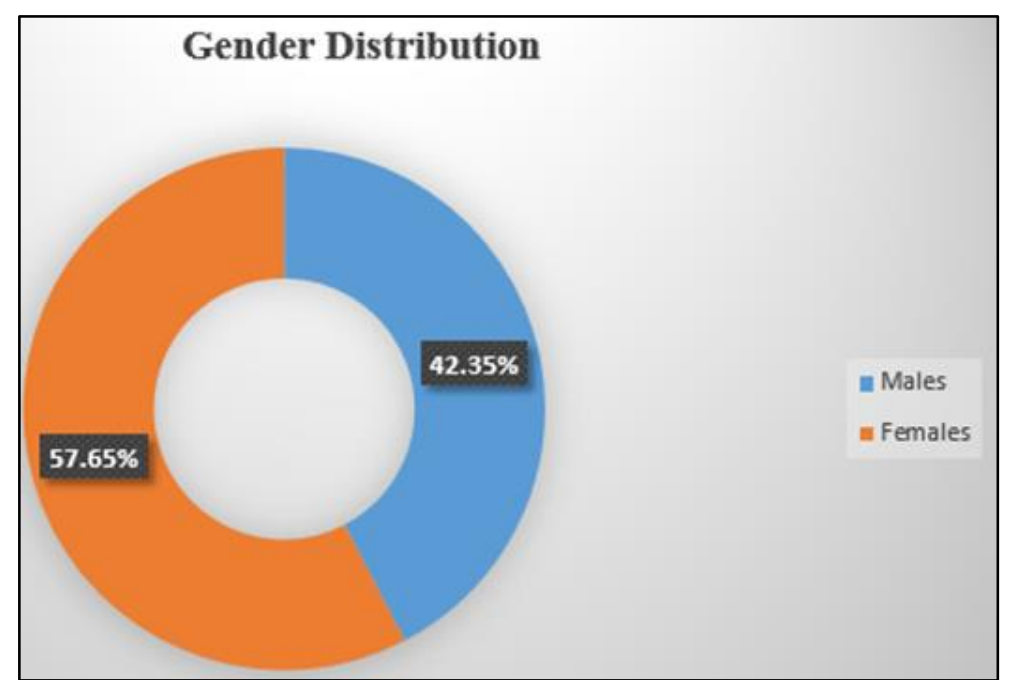


Fig. 1: Gender distribution among study group.

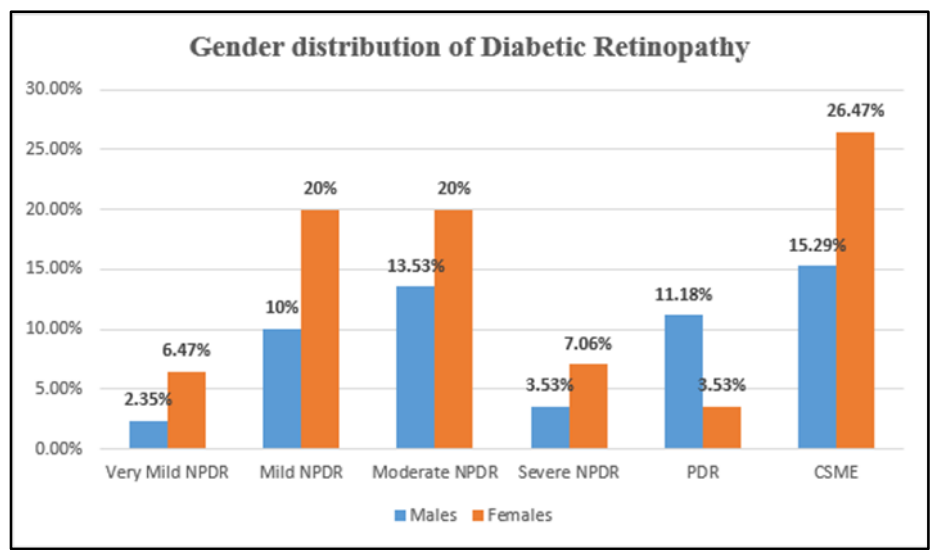

Fig. 2: Gender distribution of Diabetic Retinopathy among study group.

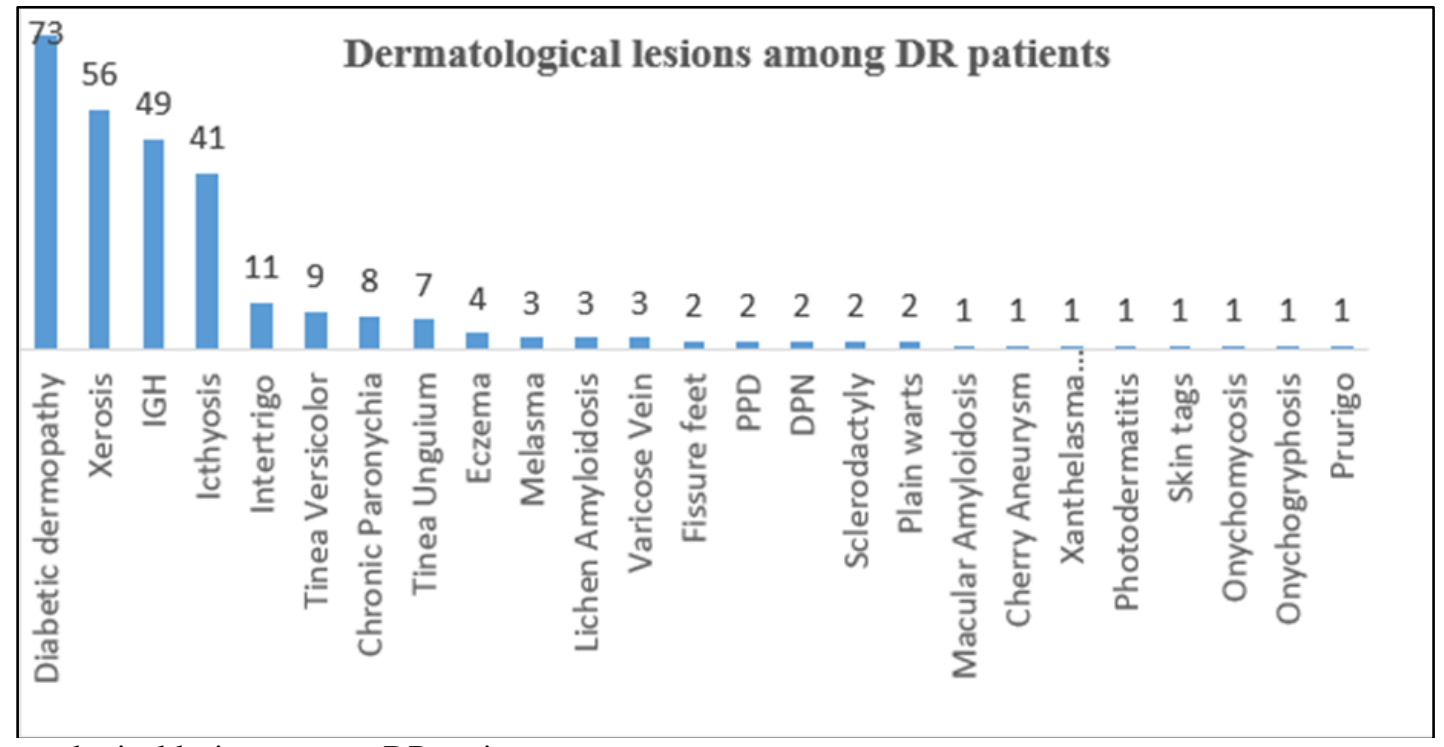

Fig. 3: Dermatological lesions among DR patients.

\section{Conclusion}

In our study, we found that the prevalence of dermatological lesions among DR patients was $86.47 \%$ and it was high among poor glycemic control patients with a prevalence of $51.18 \%$ as compared to good glycemic control patients with 32.94\%. The most common Dermatological Diabetic dermopathy (shin spots), $42.94 \%$ was the most prevalent among the dermatological lesions.

\section{Source of Funding: None.}

\section{Conflict of Interest: None.}

\section{References}

1. Wild S, Roglic G, Green A, Sicree R, King H. Global prevalence of diabetes-estimates for the year 2000 and projections for 2030. Diabetes Care 2004;27(3):1047-53.

2. King H, Aubert RE, Herman WH. Global burden of diabetes, 1995-2025: prevalence, numerical Estimates, and Projections. Diabetes Care 1998;21(9):1414-31.
3. Kaveeshwar SA, Cornwall J. The current state of Diabetes Mellitus in India. Australas Med J. 2014; 7(1): 45-48.

4. Deshpande AD, Harris-Hayes M, Schootman M. Epidemiology of Diabetes and Diabetes-related complications. Phys Ther 2008;88(11):1254-64.

5. Sreedevi C, Car N, Pavlić-Renar I. Dermatological lesions in Diabetes Mellitus. Diabetologia Croat. 2002;31(3):147-59.

6. Ngo BT, Hayes KD, DiMiao DJ, Manifestations of cutaneous diabetic microangiopathy. Am J Clin Dermatol. 2005; 6:22537.

7. Paron N G, \& Lambert, P. W. Cutaneous Manifestations of Diabetes Mellitus. Primary Care 2000;27(2):371-83.

8. Ferringer T, Miller O F III. Cutaneous manifestations of diabetes mellitus. Dermatol Clin. 20. 2002; 483-92.

9. Perez M I \& Kohn S R. (1994). Cutaneous manifestations of diabetes mellitus. J Am Academy Dermatol 1994;30(4):519-31.

10. Juturu V. Skin Health and Metabolic Complications. Bioactive Dietary Factors and Plant Extracts in Dermatology. Springer 2013;39-47.

11. G. Romano, G. Moretti, A. Di Benedetto, C. Giofre, E. Di Cesare, G. Russo et al, Cucinotta. Skin lesions in diabetes mellitus: prevalence and clinical correlations. Diabetes Res Clin Pract. 1998;39(2):101-6. 
12. Shemer A, Bergman R, Linn S, Kantor Y, Friedman-Birnbaum R. Diabetic dermopathy and internal complications in diabetes mellitus. Int J Dermatol. 1998; 37(2):113-5.

13. Demirseren DD, Emre S, Akoglu G, Arpaci D, Arman A, Metin A. et al. Relationship between skin diseases and extracutaneous complications of diabetes mellitus: clinical analysis of 750 patients. Am J Clin Dermatol. 2014;15(1):6570.

14. Abdollahi A, Daneshpazhooh M, Amirchaghmaghi E, Sheikhi $\mathrm{S}$, Eshrati B, Bastanhagh MH et al. Dermopathy and retinopathy in diabetes: is there an association? Dermatol. 2007;214(2):133-6.

15. Mirhoseini M, Saleh N, Momeni A, Deris F, Asadi-Samani M.A study on the association of diabetic dermopathy with nephropathy and retinopathy in patients with type 2 diabetes mellitus. J Nephropathol. 2016;5(4):139-43.

16. Bauer MF, Levan NE, Frankel A, Bach J. Pigmented pretibial patches. A cutaneous manifestation of diabetes mellitus. Arch Dermatol 1966;93:282-6.

17. Hosseini MS, Ehsani AH, Panah FH, Azizi F. The correlation between skin lesions, micro albuminuria and other microvascular complications in type 2 diabetic patients. Nephro Urol Mon. 2010;2(4):553-60.

18. Yosipovitch G, Hodak E, Vardi P, Shraga I, Karp M, Sprecher E et al. The Prevalence of Cutaneous Manifestations in IDDM Patients and Their Association with Diabetes Risk Factors and Microvascular Complications. Diabetes Care. 1998;21(4):5069.

19. Yau JWY, Rogers SL, Kawasaki R, Lamoureux EL, Kowalski JW, Bek T et al. (2012). Global Prevalence and Major Risk Factors of Diabetic Retinopathy. Diabetes Care. 2012;35(3):556-64

20. Rema M, Premkumar S, Anitha B, Deepa R, Pradeepa R, Mohan V et al. Prevalence of Diabetic Retinopathy in Urban
India: The Chennai Urban Rural Epidemiology Study (CURES) Eye Study, I. Clin Epidemiol Res 2005;46:2328-33.

21. Raman R, Rani PK, Rachepalle SR, Gnanamoorthy P, Uthra S, Kumaramanickavel G et al. (2009). Prevalence of Diabetic Retinopathy in India. Ophthalmol. 2009;116(2):311-8.

22. Gadkari SS, Maskati QB, Nayak BK. Prevalence of diabetic retinopathy in India: The All India Ophthalmological Society Diabetic Retinopathy Eye Screening Study 2014. IJO 2016;64(1):38-44.

23. Zhang X, Saaddine J B, Chou C-F, Cotch M F, Cheng Y J, Geiss L S, Klein R et al. Prevalence of Diabetic Retinopathy in the United States, JAMA. 2005-2008304(6):649.

24. Chakrabarty A, Norman AR, Phillips TJ. Feature: cutaneous manifestations of diabetes. Wounds. 2002;14(8):267-74.

25. Masharani U. Diabetes mellitus and hypoglycemia. In: McPhee SJ, Papadakis MA, editors. Current medical diagnosis \& treatment. 46th ed. New York: McGraw-Hill, 2007;1219-1265.

26. Bourke J. Skin disorders in Diabetes Mellitus. In: Griffiths EM C, Barker J, Bleiker T, Chalmers R, Creamer D, editors. Rook's textbook of Dermatology. Vol 2. $9^{\text {th }}$ ed. Hoboken (NJ): Wiley-Blackwell; 2016. p 64.1-64.7.

27. George S MC, Walton S. Diabetic Dermopathy. Br J Diabetes Vasc Dis. 2014; 14(3): 95-97.

28. J Kalsy, S.K. Malhotra, S. Malhotra. Incidence of diabetic dermopathy. J Pak Assoc Dermatologists. 2012;22(4):331-5.

29. Chatterjee N, Chattopadhyay C, Sengupta N, Das C, Sarma N, Pal SK. An observational study of cutaneous manifestations in diabetes mellitus in a tertiary care Hospital of Eastern India. Indian J Endocrinol Metabol. 2014;18(2):217-20.

How to cite this article: Shimna CP, Goudinho S, Samson JF, Jacob JM, Gopakumar S. Prevalence of dermatological lesions in diabetic retinopathy, Indian J Clin Exp Ophthalmol. 2019;5(3):305-9. 